\title{
DINAMIZANDO UM PROTOCOLO DE ORIENTAÇÃO PROFISSIONAL
}

\section{ANA BEATRIZ DUPRÉ SILVA, RAFAELA DE ABREU MARTINS.}

\begin{abstract}
RESUMO - Sabe-se que durante o período da adolescência o indivíduo precisa tomar decisões em relação ao seu futuro [5] e, diante da necessidade de escolha por uma profissão, a Orientação Profissional tem sido apresentada como um suporte nesse processo. Destaca-se o trabalho da psicóloga Cynthia Borges de Moura [19], que propôs um Programa-Modelo de Orientação Profissional, baseado na Análise do Comportamento, que contém atividades vivenciais além de materiais que exigem as práticas de leitura e escrita. Assim, a presente pesquisa teve por objetivo traçar adaptações a este protocolo, para que ele se tornasse mais dinâmico quando utilizado com indivíduos pouco letrados, numa pesquisa qualitativa, descritiva, aplicada, com levantamento de campo e ex post facto. A amostra foi composta por 20 participantes, que relataram suas experiências na condução de grupos. Por meio da análise do conteúdo verbalizado pelos participantes foi proposta uma releitura do Programa.
\end{abstract}

PALAVRAS-CHAVE - Escolha Profissional; Orientação Profissional; Análise do Comportamento.

\section{INTRODUÇÃO}

A adolescência pode ser caracterizada como uma fase de inúmeras transições, corporais e psicológicas. O indivíduo precisa se desprender do papel de criança, assumir uma nova identidade e buscar adaptação a ela [1]. Para Almeida e Pinho [5], é um período de tomadas de decisões em relação ao futuro, havendo uma necessidade da escolha de uma profissão. Tal escolha pode ser influenciada por fatores como a percepção que a pessoa tem a respeito de si, do mundo, do conhecimento sobre a realidade das profissões, além das influências externas como as sociais e principalmente familiar.

Diante dessa perspectiva, a Orientação Profissional tem sido desenvolvida com o intuito de dar suporte nesse processo de decisão, facilitando-o ao promover autoconhecimento e compreensão dos aspectos influenciadores, incluindo o entendimento acerca do meio no qual o sujeito está inserido [15].

Neste cenário, destaca-se a pesquisa da psicóloga e doutora Cynthia Borges de Moura que, tendo como embasamento teórico os pressupostos da Análise do Comportamento para produzir um conteúdo diferente dos modelos psicodinâmicos existentes, propôs um programa-modelo de Orientação Profissional, com diferentes atividades de leitura e escrita [19].

Tal programa tem sido utilizado num projeto de extensão universitária há 5 anos e, a partir desta experiência, foram detectadas dificuldades de adolescentes pouco letrados durante a execução dos grupos. Assim, o presente estudo teve como objetivo traçar adaptações a este Protocolo.

No que se refere ao termo "pouco letrados", é importante destacar a diferença entre "alfabetização" e "letramento", apesar de serem termos interligados. Um indivíduo pode ser considerado alfabetizado quando já passou pelo processo de aprender a ler e a escrever, tendo capacidade para tal e, letrado, quando consegue utilizar, com propriedade, a leitura e a escrita nas práticas sociais, nos diferentes contextos de sua vida [2].

E para cumprir este objetivo foram mapeados os objetivos de cada encontro e suas respectivas atividades; levantadas as principais dificuldades e facilidades encontradas pelos condutores de grupo que replicaram o Protocolo; e descritas as dinâmicas de grupo que poderiam substituir as atividades do Programa e/ou torná-las mais dinâmicas, promovendo maturidade sobre a escolha profissional.

\section{A. O DESENVOLVIMENTO HUMANO DURANTE O PERÍODO DA ADOLESCÊNCIA}

Segundo o Estatuto da Criança e do Adolescente (ECA), no Brasil a adolescência é compreendida entre os 12 e 18 anos de idade [11].

Para Papalia e Feldman, esse estágio “(...) envolve mudanças físicas, cognitivas, emocionais e sociais e assume formas variadas em diferentes contextos sociais, culturais e econômicos" [22], o que permite a compreensão do porquê esse momento pode ser considerado como de muito estresse e turbulência emocional, já que o adolescente precisa se adaptar a muitas mudanças.

A puberdade, também presente na adolescência, é o processo no qual o indivíduo passa por modificações biológicas 
e corporais até atingir a maturidade sexual e a capacidade de reprodução, ocorrendo desde a meninice [22]. É importante enfatizar que a adolescência pode ser vista como um fenômeno psicossociológico e, apesar de estar relacionada com a puberdade, são conceitos distintos [21].

Ao atingir a adolescência, a identidade construída até o momento se torna ineficaz, o que resulta na busca por uma nova, que satisfaça às necessidades da vida adulta, incluindo escolhas relacionadas à vida profissional, sexual e religiosa, o que, consequentemente, pode gerar confusão de papéis [7].

Assim, é por meio da construção de grupos que o indivíduo pode sentir mais segurança, além de "atingir uma visão integrada de si, o que inclui seus próprios padrões de crenças, metas profissionais e relações" [7].

Para Erikson [22], a confusão de papéis pode causar um atraso no amadurecimento psicológico do indivíduo, mas não o caracteriza como patológico. $\mathrm{O}$ autor afirma que essa condição se reflete de forma evidente nos comportamentos dos adolescentes, que muitas vezes podem ser denominados como "comportamentos caóticos".

Denissen, Van Aken e Dubas [22], trazem que esse também é um momento de mudanças significativas para os pais dos adolescentes e as divergências podem resultar em conflitos.

As relações amorosas também são presentes durante a adolescência [14] e, atualmente, é possível visualizar que os adolescentes estão iniciando a vida sexual mais cedo [23].

No que se refere à inserção dos adolescentes no mercado de trabalho, é importante mencionar que muitas vezes os adolescentes podem adentrar no mercado de trabalho de maneira informal, por vários motivos: necessidade de contribuição na renda familiar, o desejo dos pais para que seus filhos tenham um trabalho e sejam independentes, além de uma visão positiva desse laboro, visto como uma forma de obter dignidade [20].

\section{B. ANÁLISE DO COMPORTAMENTO E O PROCESSO DE ESCOLHA PROFISSIONAL}

Tendo como base a filosofia do Behaviorismo Radical, a Análise do Comportamento é a ciência cujo objeto de estudo é o comportamento, considerado como as interações estabelecidas entre o organismo e o ambiente [3].

Skinner [24] afirma que o comportamento sofre influência da filogenia (aspectos biológicos e evolucionários), ontogenia (histórico comportamental de vida) e cultura (meio do qual o indivíduo pertence). É também complexo, e "desde que é um processo, e não uma coisa, não pode ser facilmente imobilizado para observação. É mutável, fluido e evanescente (...)" [24].

Quanto à frequência dos comportamentos, Skinner [24] traz que quando as consequências de um comportamento aumentam as chances do comportamento ocorrer novamente, seja pela apresentação de um estímulo reforçador ou pela retirada de um estímulo aversivo do meio, na forma de esquiva ou fuga, dá-se o nome "reforço positivo" e "reforço negativo", respectivamente.
Quando a situação é a inversa, diminuindo a probabilidade da ocorrência do comportamento, pela apresentação de um estímulo aversivo ou pela retirada de um reforçador, dá-se o nome "punição positiva" e "punição negativa", respectivamente [24].

Cabe ressaltar também que, na presença de contingências previamente planejadas, é possível a obtenção de comportamentos específicos em determinados contextos, com consequente desenvolvimento dos repertórios comportamentais desejados [17].

No que se refere ao comportamento de fazer escolhas, Skinner [24] considera-o como o processo de manipular variáveis. Então, ensinar um indivíduo a fazer escolhas é o mesmo que auxiliá-lo na identificação e análise de variáveis presentes no contexto [24].

Assim, no programa de Orientação Profissional baseada na Análise do Comportamento busca-se orientar os adolescentes na tomada de decisão proporcionando um maior conhecimento acerca das opções profissionais, apresentandolhes informações importantes sobre cada uma das profissões de interesse, fornecendo subsídios para que consigam chegar a uma escolha final, entendendo muitas variáveis existentes e as consequências de cada uma delas [19].

E, por se tratar de uma intervenção em contexto grupal, há sempre um modelo objetivo, claro e conciso a ser seguido [12]. Porém, é importante lembrar que tais Protocolos devem ser utilizados como elementos norteadores, visto que, tendo um olhar profissional, é necessário que se observem as variáveis presentes e a população em questão, a fim de que sejam alcançados melhores resultados.

\section{UMA NOVA PERSPECTIVA EM ORIENTAÇÃO PROFISSIONAL}

A proposta de um programa de Orientação Profissional sob o enfoque da Análise do Comportamento foi criada por Cynthia Borges de Moura, durante o seu mestrado na Pontifícia Universidade Católica de Campinas, concluído no ano de 2000 [19].

O programa-modelo é estruturado em 10 sessões e conta com atividades que envolvem leitura, escrita, pesquisa e entrevista com profissionais, além de inúmeras reflexões sobre o processo de escolha, tendo como objetivos gerais:

1. Analisar junto aos adolescentes as variáveis controladoras (pessoais, familiares, sociais, contextuais) implicadas na escolha da carreira profissional; 2. Levar o adolescente a observar e discriminar as relações existentes entre escolha profissional e história de vida e, como a escolha de uma profissão está diretamente ligada às escolhas que aprendemos a fazer ao longo da vida; 3. Desenvolver habilidades necessárias para a escolha, a partir do fortalecimento das respostas que compõem o comportamento de tomada de decisão [19].

Para isso, o Protocolo foi estruturado em três etapas. A primeira objetivando o autoconhecimento, a segunda o conhecimento da realidade das profissões e a terceira o apoio à tomada de decisão. Na primeira e segunda etapa o indivíduo 
deve ampliar seu olhar acerca de características que são relevantes para a escolha profissional, bem como para características de cada profissão, a fim de que possa haver uma ampliação das opções a serem consideradas para escolha. $\mathrm{Na}$ sequência, a terceira etapa busca promover situações para que haja a restrição e exclusão de opções, observando critérios de escolha e permitindo então a tomada de decisão consciente [18].

\section{A ORIENTAÇÃO PROFISSIONAL E O EMPODERAMENTO DE CLASSES}

De forma geral, ao trabalhar atividades que promovem o autoconhecimento, o conhecimento da realidade das profissões e do mercado de trabalho, bem como uma tomada de decisão consciente e crítica da realidade, pode-se afirmar que o adolescente ganha autonomia e responsabilidade por suas próprias escolhas, independentemente de sua renda e condição social [4].

Assim, o processo de Orientação Profissional “(...) tem importante papel também na direção da mudança social ao propor uma reflexão sobre o futuro que cada sujeito busca construir não só individualmente, mas coletivamente" [4]. Logo, pode-se afirmar que tais programas possibilitam, por meio de reflexões e informações, que os adolescentes de classes econômicas menos privilegiadas possam ser protagonistas e agentes de mudança de suas próprias realidades, para que haja o desenvolvimento individual e social, promovendo, consequentemente, saúde e mais qualidade de vida [4].

É importante mencionar que, por vezes, mesmo que o processo de Orientação Profissional possibilite aos adolescentes de classes sociais menos favorecidas mais autonomia e empoderamento, ainda assim, alguns desses indivíduos acabam encontrando limitações no seu processo de escolha, em decorrência de suas realidades financeiras, o que implica na necessidade de seguirem outros caminhos profissionais diferentes do desejado [6]. Essa realidade reforça a importância de políticas públicas, como programas, ações e atividades promovidas pelo governo, envolvendo a participação tanto de instituições públicas como privadas, com o objetivo de assegurar o direito de cidadania para determinada classe social [13].

Alguns exemplos de políticas públicas criadas pelo Governo Federal são o Programa Universidade Para Todos (ProUni), no qual são ofertadas bolsas de estudos aos indivíduos em universidades privadas; Programa de Financiamento Estudantil (FIES), no qual os indivíduos podem financiar dada porcentagem da mensalidade do curso em que estão matriculados (também em instituições privadas), além de outros, como Programa de Inclusão Social e Racial, presente nos vestibulares das instituições públicas de ensino superior, possibilitando assim mais acesso dos acadêmicos de classes sociais menos favorecidas às faculdades, o que pode transformar a realidade de muitos adolescentes mesmo diante de todas as limitações [8].

\section{METODOLOGIA}

A pesquisa teve finalidade metodológica aplicada, natureza qualitativa e objetivo descritivo. O procedimento utilizado foi levantamento de campo e ex-post-facto, assim cada participante precisou recordar suas próprias vivências.

O estudo foi realizado no período de 28/02/2019 à 28/03/2019, nas dependências do Centro Universitário Luterano de Palmas (CEULP/ULBRA), localizado na Avenida Joaquim Teotônio Segurado, 1501 - Plano Diretor Sul, Palmas - TO, 77000-900.

Cabe ressaltar que todos os aspectos éticos previstos em legislação foram seguidos, estando em conformidade com a Resolução 466/12 que dispõe sobre pesquisas que envolvem seres humanos [16].

Assim, após a aprovação do Comitê de Ética em Pesquisa (CEP) do CEULP para a realização da pesquisa (Parecer $\mathrm{n}^{\circ}$ 3.139.219 e CAAE $n^{\circ}$ 03572218.1.0000.5516), os 36 indivíduos que compõem o universo total foram convidados a participar do estudo, de forma voluntária e mediante assinatura do Termo de Consentimento Livre e Esclarecido (TCLE).

A amostra foi composta por 20 participantes que assinaram o TCLE, sendo 10 acadêmicos e 10 egressos do curso de Psicologia da instituição, que já conduziram grupos do projeto de extensão "Orientação Profissional", replicando o Protocolo proposto por Moura [19]. Foram excluídos da amostra aqueles que não tiveram disponibilidade de horário para participar das entrevistas.

Foi realizado apenas um encontro com cada participante, individualmente e com duração de aproximadamente uma hora cada. Para a coleta de dados foi utilizado um roteiro de entrevista semiestruturado, construído de forma livre pela pesquisadora, com perguntas referentes à experiência dos condutores.

Os resultados obtidos foram analisados a partir da Análise Comportamental do Discurso (ACD), sendo esta embasada nos pressupostos do Behaviorismo Radical, proposto por Skinner [10].

$\mathrm{Na}$ ACD há a interpretação da função de um conjunto de comportamentos verbais, ou seja, do discurso [10]. E para tal é realizada a seleção de segmentos verbais de interesse, separando-os em categorias [25].

No presente estudo as categorias delineadas para análise foram duração do programa, participação de adolescentes pouco letrados nos grupos de Orientação Profissional, possíveis dificuldades dos adolescentes para realização das atividades propostas, engajamento e colaboração dos adolescentes nos grupos, comportamentos e características próprios da adolescência, influências no processo de escolha, número de atividades de leitura e escrita, possíveis dificuldades por parte dos condutores na replicação do Protocolo, adaptações durante a replicação, modificação dos anexos e experiência como condutores dos grupos replicando o Protocolo de Moura [19].

Após a categorização houve a identificação das relações funcionais e são analisadas as variáveis ambientais presentes 
que podem influenciar e/ou controlar o discurso apresentado [25].

\section{RESULTADOS}

Por meio da aplicação da entrevista semiestruturada foi possível levantar que metade (10) dos participantes da pesquisa acredita que a duração de 10 sessões seja adequada.

Quanto à participação de adolescentes pouco letrados, apenas 4 condutores tiveram a presença desses indivíduos em seus grupos. Cabe ressaltar que entre os outros 16 participantes que não tiveram esse contato, 2 ressaltaram a presença de 1 adolescente com diagnóstico de TDAH.

Quanto à possível dificuldade por parte dos adolescentes (mesmo não sendo pouco letrados) na realização das tarefas, 12 participantes responderam que não houve dificuldades, mas entre eles, um mencionou a reclamação dos adolescentes por serem muitas atividades de escrita, 2 mencionaram certo desinteresse dos adolescentes para a realização das tarefas e 1 relatou que as perguntas feitas pelos adolescentes eram voltadas mais para o esclarecimento de dúvidas simples.

No que diz respeito ao engajamento e à postura colaborativa dos adolescentes nos grupos, 12 participantes relataram que não houve total engajamento e colaboração positiva por parte dos adolescentes.

Foram observadas, ainda, características e/ou comportamentos próprios da adolescência. Os voluntários do estudo verbalizaram a presença de acnes nos adolescentes, o uso de vestimentas próprias da idade, a forma de assentar-se, os adereços utilizados por cada um, problemas familiares, falas agressivas, comportamentos de inquietude, confusão, passividade, angústia, desatenção, vaidade e estabelecimento de subgrupos e de relacionamentos dos indivíduos com pessoas do sexo oposto.

Outro participante da pesquisa também verbalizou a existência de adolescentes que desde muito cedo estavam inseridos no mercado de trabalho informal, para auxiliar financeiramente em casa e 3 outros mencionaram a paternidade e maternidade presente nos grupos conduzidos. Quanto à influência no processo de escolha, 16 mencionaram a variável familiar, 6 de pessoas próximas/amigos, e 5 da própria instituição escolar.

Já no que se refere ao número de atividades de leitura e escrita, mais da metade dos participantes considera alta a quantidade de tarefas a serem desenvolvidas, o que reforça a necessidade de adaptação da proposta.

Quanto à possível dificuldade na replicação do Protocolo, apenas 8 participantes relataram que tiveram dificuldades, seja para compreender as instruções e/ou referencial teórico, como para administrar a quantidade de anexos a serem aplicados, além da falta de conexão entre o referencial teórico no Protocolo e a realidade dos grupos.

Quanto às atividades que os participantes da pesquisa tiveram maior facilidade para executar, tem-se a apresentação dos vídeos (5 mencionaram). Cabe ressaltar que essa atividade não está no Protocolo original e já se trata de uma adaptação feita ao longo dos anos de aplicação, pela dificuldade dos adolescentes em procederem às entrevistas solicitadas.

Quanto à replicação do Programa, todos os participantes da pesquisa relataram que fizeram adaptações às atividades e/ou anexos.

E, no que diz respeito ao uso dos anexos do Programa, utilizados durante a replicação, os participantes relataram que mudaram e/ou mudariam principalmente os anexos 4 (17 mencionaram), 2 (12 mencionaram) e 8 (11 mencionaram).

Quanto à participação no Projeto de Extensão, 10 participantes mencionaram que o Protocolo de Moura [19] serviu como um bom suporte, mas precisa passar por algumas alterações em suas atividades.

\section{DISCUSSÃO}

Por meio da análise dos relatos de experiência e dados levantados com a aplicação da entrevista, foi possível identificar algumas temáticas importantes.

Os participantes mencionaram algumas características biológicas e físicas (crescimento da barba, voz em processo de mudança, corpo das meninas em crescimento e presença de acnes) observadas nos adolescentes que faziam parte dos grupos de Orientação, e estas vão ao encontro com o que Papalia e Feldman [22] e Palácios [21] trazem em seus estudos, quando abordam as transformações biológicas e corporais que ocorrem nesse período da vida. Quanto à presença de "panelinhas" e subgrupos, que também foram apontadas pelos participantes, Bee [7] explica que, na busca pela identidade, os adolescentes tendem a formar grupos para que possam se sentir mais seguros durante essa fase.

Erikson (apud Bee [7]), acrescenta que os adolescentes podem precisar de um tempo maior para o amadurecimento psicológico, em decorrência da confusão de papéis vivenciada durante esse período, o que pode explicar a imaturidade mencionada pelos participantes da pesquisa.

Um dos voluntários mencionou ainda a dificuldade de relacionamento dos adolescentes com seus pais, o que é confirmado por Denissen, Van Aken e Dubas [22], que enfatizam a necessidade de adaptação de ambos a uma nova realidade.

Quanto ao relato de relacionamento dos adolescentes com outros do sexo oposto, Justo [14] aborda que são bem presentes durante essa fase da vida. E quanto à maternidade e à paternidade presentes durante a adolescência, Silva, Silva e Alves [23] explicam que os adolescentes estão começando a ter vida sexual ativa cada vez mais cedo.

Com relação à participação dos adolescentes no mercado de trabalho desde muito cedo, Oliveira e Robazzi [20] trazem em seus estudos algumas hipóteses, entre elas, há a de que os indivíduos possuem a necessidade de auxiliar financeiramente em casa, o que de fato era a realidade dos adolescentes presentes nos grupos conduzidos, segundo um dos voluntários da pesquisa.

De forma geral, os estereótipos e características comportamentais observados pelos condutores nos adolescentes também podem ser confirmados por Aberastury [1]. 
Quanto ao comportamento de fazer escolhas, Skinner [24] traz que este é um processo de manipulação de variáveis. O trabalho de Moura [19] aponta três variáveis importantes: pessoais, profissionais e de tomadas de decisão. Dentre as variáveis pessoais, há a influência dos familiares, apontadas por Almeida e Pinho [5], que indicam os pais como sendo a principal influência, o que foi confirmado a partir do relato dos entrevistados.

Foi possível verificar, também, na fala de um dos participantes, a autonomia e o empoderamento que o processo de Orientação Profissional pode promover aos adolescentes, o que vai ao encontro com os estudos de Aguiar e Conceição [4], quando afirmam que, independentemente da renda financeira e condição social, os indivíduos que passam pelo processo de Orientação tornam-se mais responsáveis por suas escolhas, e devem buscar a transformação de suas realidades, sendo protagonistas de suas próprias histórias.

É importante enfatizar que o processo de adaptação das atividades e modificação dos anexos realizados pelos condutores dos grupos, a fim de deixá-los mais acessíveis aos adolescentes pouco letrados e/ou com dificuldades, podem ser explicados como uma forma de arranjo de contingências, tendo em vista os preceitos básicos da Análise do Comportamento.

Moreira e Medeiros [17] trazem que, quando as contingências são previamente planejadas, é possível obter determinados comportamentos em contextos específicos.

Skinner [24] acrescenta que denomina-se "reforço" quando as consequências aumentam a probabilidade de dado comportamento ocorrer novamente. Ou seja, ao modificar as tarefas do Protocolo, tornando-as mais dinamizadas, atraentes e reforçadoras, pode haver o aumento da probabilidade do comportamento de adesão (por parte dos adolescentes) acontecer mais vezes.

$\mathrm{E}$, tendo em vista os relatos dos participantes e todos os dados levantados, além dos objetivos de cada sessão e as pesquisas realizadas sobre atividades dinamizadas, foi então elaborada uma releitura do Protocolo, que conta com a duração também de dez encontros.

Compõe a releitura o uso maior de recursos audiovisuais; a troca de dinâmicas, atividades e técnicas propostas anteriormente no Protocolo de Moura [19] por outras que cumpram o mesmo objetivo; feedback verbal ao final de cada encontro para acompanhamento semanal, e não mais escrito, como avaliação na última sessão; retirada e/ou substituição de anexos por dinâmicas que cumpram o mesmo objetivo; uso de respostas em tópicos e discussões verbais, não mais textos escritos e corridos; modificações na estrutura dos anexos; atividades de relaxamento; pesquisas em laboratórios de informática das instituições em sites das faculdades, ProUni, SiSu e demais programas; troca da atividade de dramatização por rodas de conversa; visita às instituições de ensino superior e/ou visita de acadêmicos e/ou profissionais nos grupos.

\section{CONSIDERAÇÕES FINAIS}

O presente estudo teve como objetivo final traçar adaptações ao Protocolo de Orientação Profissional sob o enfoque da Análise do Comportamento, criado por Cynthia Borges Moura [19], de forma a atender pessoas pouco letradas.

Assim, por meio dos relatos de experiência, dados levantados a partir do relato dos participantes e pesquisas sobre dinâmicas de grupo, foi possível estruturar uma releitura do Programa, tendo em vista as adaptações já realizadas pelos condutores, as modificações que fariam nos anexos e atividades, e os objetivos identificados em cada uma das sessões.

No que se refere às facilidades encontradas na execução do Projeto, segundo os relatos, pode-se afirmar que foram quanto à execução de atividades mais dinâmicas e, no que diz respeito às dificuldades, alguns fatores devem ser mencionados, como o horário em que os grupos foram conduzidos, o número de tarefas propostas e a falta de compreensão por parte dos participantes da pesquisa quanto algumas instruções para a realização das tarefas.

Além disso, foi possível verificar características físicas, biológicas e comportamentais próprias da adolescência nos participantes dos grupos de Orientação Profissional e a presença de influências no processo de escolha por uma profissão, sendo notória a influência familiar (especialmente dos pais).

É importante destacar que o número de participantes dessa pesquisa que afirmaram conduzir grupos com adolescentes pouco letrados foi minoria diante da amostra total e, apesar disso, por meio dos relatos foi possível verificar que foi unânime a opinião sobre a necessidade de modificar algumas atividades do Protocolo, para que sua replicação seja mais dinâmica.

Quanto à experiência na condução dos grupos, pode-se afirmar que esta foi satisfatória para todos os participantes da pesquisa, visto que todos a descreveram de maneira positiva, não desconsiderando os pontos que precisam ser melhorados.

Por fim, cabe ressaltar que seria interessante um outro estudo colocando em prática a nova proposta e avaliar os benefícios das atividades propostas na releitura construída neste estudo.

\section{Referências}

[1] ABERASTURY, A.; KNOBEL, M. Adolescência normal. Porto Alegre. Artes Médicas, 1981.

[2] ALMEIDA, V. F; FARAGO, A. C. A importância do letramento nas séries iniciais. Graduação-Centro Universitário UNIFAFIBE-Bebedouro -SP Cadernos de Educação: Ensino e Sociedade, Bebedouro-SP, v.1, n.1, p. 204-218, 2014.

[3] ABREU-RODRIGUES, J.; RIBEIRO, M. R., org. Análise do Comportamento: Pesquisa, Teoria e Aplicação. São Paulo: Artmed, 2005.

[4] AGUIAR, F. H. R.; CONCEIÇÃO, M. I. G. Orientação vocacional e promoção da saúde integral em adolescentes. 2013. Estudos e Pesquisas em Psicologia, v. 13, n. 1, p. 86-100.

[5] ALMEIDA, M. E. G. G.; PINHO, L. V. Adolescência, família e escolhas: Implicações na Orientação Profissional. Psicologia Clínica. Rio de Janeiro, v. 20, n. 2, p.173-184, 2008. Disponível em: $<\mathrm{http}$ //www.scielo.br/pdf/pc/v20n2/a13v20n2.pdf>. Acesso em 20 ago. 2018. 
[6] BASTOS, J. C. Efetivação de escolhas profissionais de jovens oriundos do ensino público: um olhar sobre suas trajetórias. Revista Brasileira de Orientação Profissional, 6 (2), 31-43, 2005.

[7] BEE, H. O Ciclo Vital. Porto Alegre, Ed. Artes Médicas, 1997.

[8] BONETI, L. W. Educação, exclusão e cidadania. 3. ed. Ijuí: Editora UNIJUI, 2003

[9] BORLOTI, E. et al. Análise Comportamental do Discurso: fundamentos e Método. Psicologia: Teoria e pesquisa, Brasília, v. 24, n. 1, p.101-110, mar. 2008. Disponível em: $<\mathrm{http}$ //www.scielo.br/pdf/ptp/v24n1/a12v24n1.pdf>. Acesso em 30 out. 2018.

[10] BORLOTI, E. et al. Análise comportamental do discurso: uma entrevista com uma paciente oncológica. Perspectivas em Análise do Comportamento, Vitória - ES, v. 3, n. 2, p.102-116, 2012.

[11] BRASIL. Estatuto da criança e do adolescente: Lei federal $n^{\circ} 8069$, de 13 de julho de 1990. Brasília, 1990 (vigência). Disponível em: <http://www.planalto.gov.br/ccivil_03/leis/L8069.htm>. Acesso em 17 set. 2018.

[12] COÊLHO, C.C.B.; BARROS, M.F.F. Psicoterapia Comportamental em Grupos. 2012. Disponível em: $<$ http://www.psicologia.pt/artigos/textos/TL0256.pdf>. Acesso em: 29 set. 2018

[13] CUNHA, C. G. S. Avaliação de políticas públicas e programas governamentais: tendências recentes e experiências no Brasil. Rio Grande do Sul: Secretaria de Coordenação e Planejamento, 2006.

[14] JUSTO, J. S. O "ficar" na adolescência e paradigmas de relacionamento amoroso da contemporaneidade. Revista do Departamento de Psicologia, UFF, n1. v.17. jan/jun 2005. Disponível em: <http://www.scielo.br/pdf/rdpsi/v17n1/v17n1a05>. Acesso em 21 ago. 2018.

[15] LUCCHIARI, D.H.P.S. O que é orientação profissional?: Uma nova proposta de atuação. In: LUCCHIARI, D.H.P.S. et al (Org.). Pensando e vivendo a Orientação Profissional. 3. ed. São Paulo - SP: Summus Editorial, 1993. Cap. 1. p. 7-16

[16] MINISTÉRIO DA SAÚDE (2002). Resolução n n 466/2012 Aprova diretrizes e normas regulamentadoras de pesquisas envolvendo seres humanos. Disponível em: <http://bvsms.saude.gov.br/bvs/saudelegis/cns/2013/res0466_12_12_2012.html> Acesso em 13 out. 2018.

[17] MOREIRA, M. B.; MEDEIROS, Carlos Augusto de. Princípios Básicos de Análise do Comportamento. Porto Alegre: Artmed, 2007.

[18] MOURA, C. B. Orientação profissional: Avaliação de um programa sob o enfoque da análise do comportamento. Dissertação de Mestrado. Pontifícia Universidade Católica de Campinas, 2000.

[19] MOURA, Cynthia Borges de. Orientação Profissional: sob o enfoque da análise do comportamento. 4. ed. Campinas: Alínea, 2004.

[20] OLIVEIRA, B. R. G.; ROBAZZI, M. L. C. C. O trabalho na vida dos adolescentes: alguns fatores determinantes para o trabalho precoce. Rev. Latino-Am. Enfermagem, Maio 2001, vol.9, no.3, p.83-89. ISSN 01041169. Disponível em: <http://www.scielo.br/pdf/rlae/v9n3/11503.pdf> Acesso em:18 set. 2018.

[21] PALÁCIOS, J. O que é a adolescência. In: COLL, César et al. Desenvolvimento Psicológico e Educação: Psicologia Evolutiva. 2. ed. Porto Alegre: Artmed, 2004. Cap. 20. p. 263-272.

[22] PAPALIA, D. E.; FELDMAN, R. D. Desenvolvimento Humano. 12. ed. Porto Alegre: Artmed, 2013.

[23] SIlVA, M. S; SILVA, M. R; ALVES, M. F. P. Sexualidade e adolescência: é preciso vencer os tabus. Anais do $2^{\circ}$ Congresso de Extensão Universitária. Belo Horizonte, 2004. Disponível em: $<$ https://www.ufmg.br/congrext/Educa/Educa169.pdf $>$. Acesso em: 21 ago. 2018.

[24] SKINNER, B. F. Ciência e Comportamento Humano. 11. ed. São Paulo: Martins Fontes, 2003.

[25] XAVIER, G. S. et al. Método Reno: uma proposta para análise comportamental do discurso. Perspectivas em Análise do Comportamento, Campo Grande - RS, v. 8, n. 1, p.120-134, 30 ago. 2017. Associação Paradigma - Centro de Ciências e Tecnologia do Comportamento. Disponível em: <http://pepsic.bvsalud.org/pdf/pac/v8n1/v8n1a09.pdf>. Acesso em: 30 out. 2018.

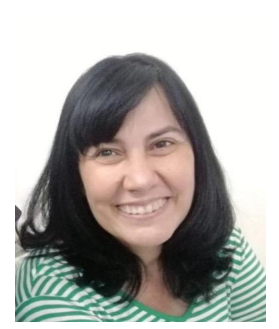

ANA BEATRIZ DUPRÉ SILVA

Bacharel em Administração de Empresas pela Universidade Católica de Brasília (1988). Psicóloga pelo Centro de Ensino Unificado de Brasília (1998), possui Formação em Terapia Comportamental pelo Instituto São Paulo de Análise do Comportamento (2000), é Mestre em Psicologia pela Universidade de Brasília (2002), Doutora em Ciências do Comportamento pela Universidade de Brasília (2012) e Analista do Comportamento Acreditada pela ABPMC (012/2018). Atualmente é professora titular do Centro Universitário Luterano de Palmas, trabalhando com Análise do Comportamento em vários contextos.

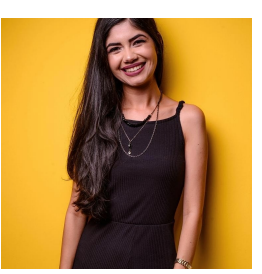

\section{RAFAELA DE ABREU MARTINS}

Psicóloga pelo Centro Universitário Luterano de Palmas (CEULP/ULBRA), pós graduanda em Gestão de Pessoas e Liderança pela Faculdade Laboro, atuando nas áreas Clínica e Organizacional. 